\title{
液相合成彩色氮化碳及其光电化学特性研究
}

\author{
何利蓉唐笑* 张灵李艳虹相国涛周贤菊 \\ 凌发令姚璐蒋浩 \\ (重庆邮电大学理学院 重庆 400045)
}

\begin{abstract}
摘要 减小带隙值和获得有序二维微结构是提高氮化碳光电化学性能的关键. 通过调控尿素和柠檬酸的比例, 采用室 温熟化工艺, 合成出不同颜色的氮化碳材料, 成功地将其带隙减小至 $1.74 \mathrm{eV}$, 并获得了由有序二维网络构建的多孔微 结构. 所得氮化碳获得了一定光电转换性能, 并随着带隙值的减小和二维网络结构的构建, 表现出少见的光诱导电荷 存储行为.
\end{abstract}

关键词 氮化碳; 光电转换; 电荷存储; 㕍电容; 太阳能

\section{Study on Photoelectrochemical Properties of Colorful Carbon Nitrides Synthesized in Liquid-Phase}

\author{
Lirong He Xiao Tang* Ling Zhang Yanhong Li Guotao Xiang Xianju Zhou \\ Faling Ling Lu Yao Hao Jiang \\ (School of Science, Chongqing University of Posts and Telecommunications, Chongqing 400045, China)
}

\begin{abstract}
Reducing the band gap value and obtaining an ordered two-dimensional microstructure are crucial to improving the photoelectrochemical performance of carbon nitrides. By adjusting the ratio of urea and citric acid and ripening the precursor at the room temperature, we synthesize the carbon nitride materials with different colors of orange, green and blue. The resultant blue sample has a narrowed band gap of $1.74 \mathrm{eV}$ and the strong absorption to the light in $550 \sim 700 \mathrm{~nm}$ wavelength range. The photoelectrochemical solar cell is fabricated using the synthesized carbon nitrides as light absorber, $\mathrm{TiO}_{2}$ as electron transporter and $\mathrm{I}_{3}^{-} / \mathrm{I}^{-}$as the redox shuttle in electrolyte. The orange carbon nitride has typical photoelectric conversion performance with $J_{\mathrm{sc}}=0.65 \mathrm{~mA} \cdot \mathrm{cm}^{-2}, V_{\mathrm{oc}}=530 \mathrm{mV}$ and $f f=0.64$. The blue carbon nitride has obvious enhanced $J_{\mathrm{sc}}$ of $1.03 \mathrm{~mA} \cdot \mathrm{cm}^{-2}$ owing to the obvious enhanced visible light absorption, while the deeply decreased ff of 0.33 . The cyclic voltammetry tests demonstrate the electrode reaction properties of the fabricated carbon nitride-based cell under illumination. It turns out that the cell based on the blue carbon nitride has obvious photo-induce pseudocapacitive behavior with an area specific capacitance of $4.9 \mathrm{mF} \cdot \mathrm{cm}^{-2}$. TEM (Transmission electron microscope), XRD (X-ray diffraction), FTIR (Fourier transform infrared spectroscopy) and XPS (X-ray photoelectron spectroscopy) reveal the microstructure characteristics of the colored carbon nitrides. The orange one is carbon nitride quantum dots with the particle size less than $10 \mathrm{~nm}$. The blue one is a carbon nitride polymer containing graphite domains with oxidized boundaries, forming three-dimensional porous structure constructed by an ordered two-dimensional network. The green one has a mixture microstructure as well as the medium photoelectrochemical properties between the former two, which are both photoelectric conversion and photo-induced charge storage performance.

Keywords carbon nitrides; photoelectric conversion; charge storage; pseudo-capacitance; solar energy
\end{abstract}

\section{1 引言}

氮化碳是以庚嗪环或三嗪环为基本结构单元形成 的碳氮聚合物 ${ }^{[1]}$. 由于其二维纳米结构、半导体特性、 低价环保、优异的物理化学稳定性、易于合成及改性等 优势特点 ${ }^{[2-5]}$, 近年来在光催化、超级电容器、太阳能电
池、锂离子或钠离子电池、燃料电池等技术领域被广泛 应用 ${ }^{[6-8]}$. 氮化碳材料被发现的特性包括: 光催化分解 水及其它有机污染物 [9]、表面对氧有强吸附及还原作 用 [10]、储能特性 ${ }^{[11-12]}$ 等. 目前制备氮化碳材料的方法主 要是先通过将含氮和碳的物质进行水热反应得到前驱

*E-mail: tangxiao@cqupt.edu.cn

Received December 19, 2020; published March 9, 2021.

Project supported by the Venture \& Innovation Support Program for Chongqing Oversea Returnee (No. CX2017023), the Construction of Double City Economic Circle in Chengdu Chongqing Region Scientific and Technological Innovation Project (No. KJCX2020028), the National Natural Science Foundation of China (Grant No. 12004061), the Science and Technology Research Program of Chongqing Municipal Education (No. KJZD-K201800602), and the Chongqing Natural Science Foundation (No. cstc2019jcyj-msxmX0525).

项目受重庆市留学人员创新支持计划重点项目(No. CX2017023)、“成渝地区双城经济圈建设”科技创新项目(No. KJCX2020028)、国家自然科学基金 青年基金(No. 12004061)、重庆市教育委员会科学技术研究重点项目(No. KJZD-K201800602)和重庆自然科学基金面上项目(No. cstc2019jcyjmsxmX0525)资助. 
物, 然后再通过高温热处理 $\left(400{ }^{\circ} \mathrm{C}\right.$ 以上)获得氮化碳材 料 [13]. 该制备方法易于形成庚嗪环结构. 以庚嗪环为基 本结构单元的氮化碳带隙值较宽, 为 $2.7 \mathrm{eV}$ 左右 ${ }^{[14]}$, 因 而只能吸收太阳光谱中波长小于 $450 \mathrm{~nm}$ 的光, 而对太 阳光谱中比例很高的可见光吸收较弱, 几乎不具备光电 转换能力 ${ }^{[15]}$, 大大局限了其在光电相关技术领域的应 用. 此外, 庚嗪环基的氮化碳材料, 在非晶态时以氨基 桥连, 通过氨基上的氢与庚嗪环上的氮原子之间形成氢 键来构建二维纳米结构, 因而在高温下进行缩聚或晶化 时, 通常导致杂乱无规则的微观形态 ${ }^{[16]}$, 严重影响其对 自由电荷的存储性能, 这大大降低了其在储能技术方面 的应用.

研究发现, 以三嗪环为基本结构单元的氮化碳具有 更低的带隙值 ${ }^{[17]}$; 在氮化碳中引入石墨域也有利于其 带隙值的降低 ${ }^{[18]}$. 本工作通过调控反应物中氮源(尿素) 和碳源(柠檬酸)的比例, 在氮化碳中引入石墨域; 采用 室温熟化工艺, 以避免高温热处理对微结构有序性的破 坏, 获得了不同颜色的氮化碳材料. 通过紫外可见吸收 光谱及透射光谱、光致苂光发射光谱(PL)、 $X$ 射线衍射 谱 $(X R D) 、$ 透射电子显微镜(TEM)、 $X$ 射线光电子能谱 (XPS)、傅里叶变换红外光谱(FTIR)等方法对所得氮化 碳材料的微观形态、微结构性质及光吸收特性进行了分 析表征. 并将其制备成光电极, 分析测试了光电转换性 能、循环伏安特性、恒电流充放电性能等光电化学特性.

\section{2 结果与讨论}

\section{1 光吸收性质}

柠檬酸和尿素以 $1: 10 、 1: 1 、 1: 0.5$ 的质量比混 合, 在 $200{ }^{\circ} \mathrm{C}$ 下水热反应 $3 \mathrm{~h}$. 所得水热反应产物在室 温下熟化 $30 \mathrm{~d}$, 分别获得了橙色、绿色、蓝色三种不同 颜色的样品(图 1a). 紫外可见吸收光谱表明三种颜色样 品具有不同的光吸收性质. 橙色样品在 $475 \mathrm{~nm}$ 处出现 吸收峰, 绿色样品在 $635 \mathrm{~nm}$ 处出现吸收峰, 蓝色样品则 表现出对 $639 \mathrm{~nm}$ 波长光的强吸收(图 1b). 根据样品的 紫外可见透射光谱(图 1c)和 Tauc 图(图 1d 1f), 得到橙 色样品 $\left(m_{\text {柠模酸 }}: m_{\text {尿素 }}=1: 10\right)$ 、绿色样品 $\left(m\right.$ 柠檬酸 $: m_{\text {尿素 }}$ $=1: 1)$ 、蓝色样品 $\left(m_{\text {柠榢酸 }}: m_{\text {尿素 }}=1: 0.5\right)$ 的光学带隙值 $\left(E_{\mathrm{g}}\right)$ 分别为 $2.26 \mathrm{eV} 、 2.24 \mathrm{eV}$ 和 $1.69 \mathrm{eV} 、 1.74 \mathrm{eV}$. 可见, 随着柠檬酸和尿素质量比的增加, 所合成产物对可见光 的吸收性质逐渐增强, 光学带隙值出现显著减小. 值得 注意的是, 当柠檬酸和尿素质量比为 $1: 0.5$ 时, 所得产 物表现出对 550 700 nm 波段可见光的强吸收且光学带 隙值降低到 $1.74 \mathrm{eV}$.

\section{2 微结构性质}

TEM 图揭示了不同颜色样品的微观形貌. 在橙色 样品中发现尺寸小于 $10 \mathrm{~nm}$ 且均匀分散的小颗粒(图 2a); 绿色样品中发现具有显著二维结构的网络状聚集体, 且

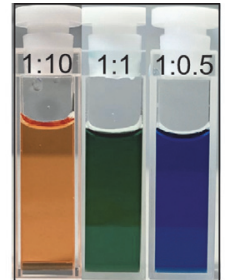

(a)
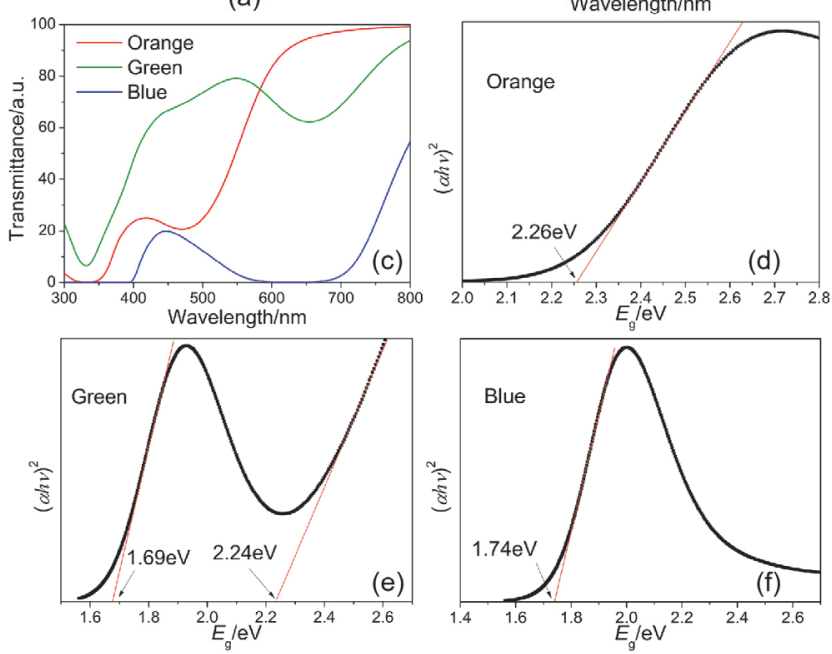

图 1 三种不同颜色样品的(a)照片, (b)吸收光谱和(c)透射光谱及相应 的 Tauc 图和光学带隙值: (d)橙色, (e)绿色, (f)蓝色

Figure 1 (a) Pictures, (b) absorption spectra and (c) transmission spectra of different color samples. Tauc plots and optical band gap values of (d) orange, (e) green and (f) blue samples

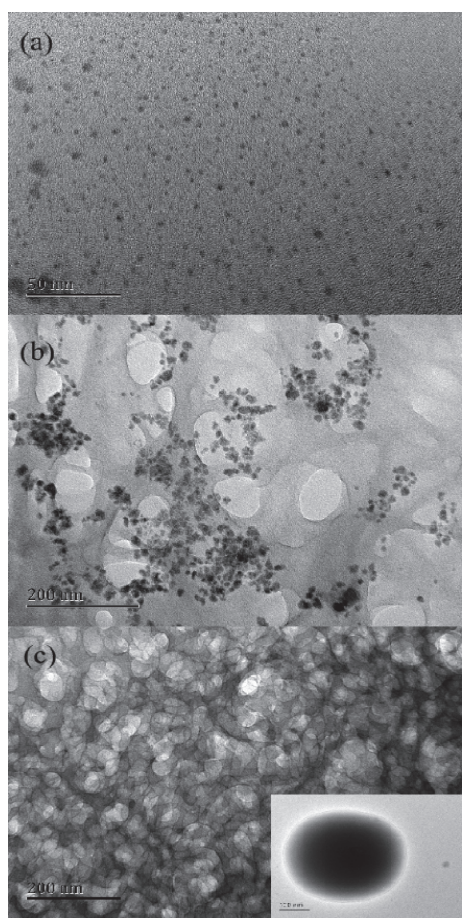

图 2 柠檬酸与尿素以不同质量比反应所得样品的 TEM 图片: (a) 1 : 10 (橙色), (b) $1: 1$ (绿色), (c) $1: 0.5$ (蓝色)

Figure 2 TEM images of samples obtained when the mass ratio of citric acid to urea are (a) $1: 10$ (orange), (b) $1: 1$ (green) and (c) $1: 0.5$ (blue) 
在网络表面附着了大量小颗粒(图 2b); 蓝色样品中发现 了较大尺寸的球形颗粒, 这些球形颗粒具有二维网络构 成的多孔内部结构(图 2c).

将三种颜色样品冷冻干燥, 进行 XRD、FTIR 和 XPS 测试. 结果发现, 三种颜色样品的 XRD 图谱都没有明 显衍射峰(图 3a). 由于氮化碳通常需要 $400{ }^{\circ} \mathrm{C}$ 以上的高 温热处理才能结晶 ${ }^{[19]}$, 因此在室温条件下熟化获得产 物的确应该是低结晶度物质. 图 $3 \mathrm{~b}$ 为样品的 FTIR 测试 结果. 1179、1246、1425 和 $1542 \mathrm{~cm}^{-1}$ 处的四个吸收峰 是由于碳氮杂环中 $\mathrm{C}=\mathrm{N}-\mathrm{C}$ 的拉伸振动引起 ${ }^{[20]} ; 770$ $\mathrm{cm}^{-1}$ 处的吸收峰来自于三嗪环的弯曲振动 ${ }^{[21]}$. 三种颜 色样品的 FTIR 图谱上均出现了这几个代表着氮化碳聚 合物分子结构基本特征的吸收峰. 蓝色样品在 $770 \mathrm{~cm}^{-1}$ 处的吸收峰最强, 而橙色样品在 $770 \mathrm{~cm}^{-1}$ 处的吸收峰明 显减弱. 这来自于两个可能的原因: (1)蓝色样品二维结 构特征明显, 使得三嗪环的弯曲振动显著, 而橙色样品 为三维颗粒状, 因而三嗪环的弯曲振动大大减弱. (2)蓝 色样品是以三嗪环为基本结构单元的氮化碳, 因而有明 显的三嗪环弯曲振动吸收峰; 橙色样品的三嗪环进一步 缩聚形成了庚嗪环, 因而其弯曲振动吸收减弱. 蓝色样 品在 $992 \mathrm{~cm}^{-1}$ 处出现明显吸收峰, 这是由于 $\mathrm{C}-\mathrm{N}$ 面内 拉伸引起 ${ }^{[22]}$, 当在石墨域中引入了氮元素时会出现该 处的吸收峰, 表明蓝色样品中存在 $\mathrm{N}$ 掺杂石墨烯结构区 域. 橙色样品未见 $992 \mathrm{~cm}^{-1}$ 处的吸收峰, 表明橙色样品
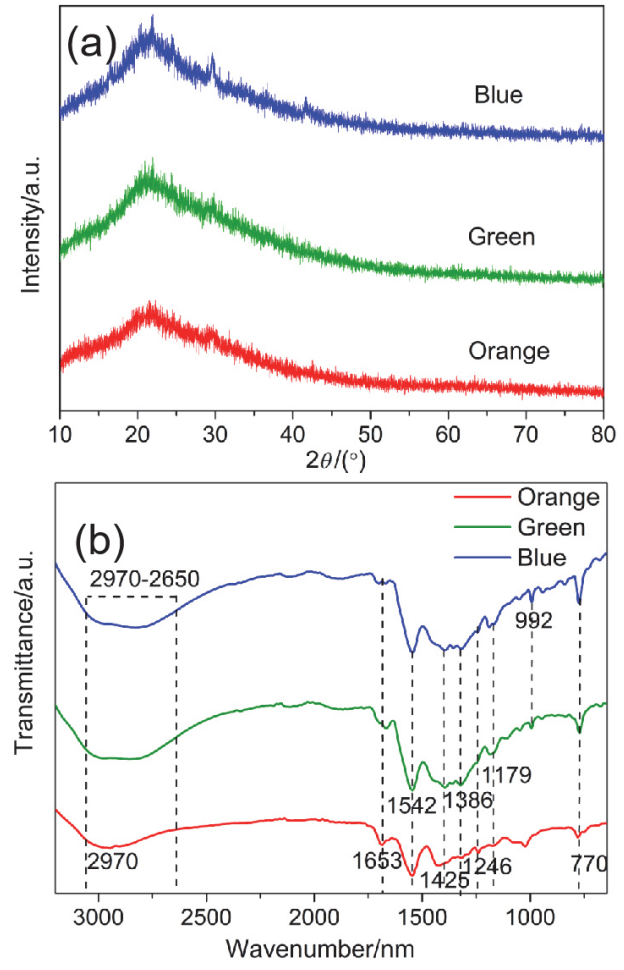

图 3 柠檬酸与尿素质量比分别为 $1: 10$ (橙色)、1：1(绿色)、1：0.5(蓝 色)时所得产物的(a) XRD 图谱和(b) FITR 光谱

Figure 3 (a) XRD patterns and (b) FITR spectra of samples obtained when the mass ratio of citric acid to urea are $1: 10$ (orange), $1: 1$ (green), and $1: 0.5$ (blue)
中不存在石墨域中掺杂 $\mathrm{N}$ 元素的结构. 此外, 蓝色和绿 色样品的 FTIR 图谱上均可见位于 $2650 \sim 2970 \mathrm{~cm}^{-1}$ 处 的宽吸收峰，是由残余氨基中的 $\mathrm{N}-\mathrm{H}$ 和表面吸附水中 的-OH 的拉伸振动以及氢键的相互作用引起的 ${ }^{[23]}$. 橙色 样品在 $2650 \mathrm{~cm}^{-1}$ 处归属于氨基的吸收峰明显较弱, 表 明其结构中残余氨基较少; 结合其微观形态为小于 10 $\mathrm{nm}$ 的小颗粒状(图 2a), 推测橙色样品为氮化碳量子点.

图 4 为三种颜色样品的 XPS 测试结果. 在样品的 XPS 总谱(图 4a)上可见高比例氧元素含量. 由于样品是 在水溶液中合成，因此均含大量表面氧化基团和表面吸 附水. 从图 $4 \mathrm{e}$ 的 $\mathrm{O} 1 \mathrm{~s}$ 分峰结果来看, 样品所含表面基团 主要是 $\mathrm{C}-\mathrm{OH}(532.9 \mathrm{eV})^{[24]}$ 和 $\mathrm{C}=\mathrm{O}(531.1 \mathrm{eV})^{[25]}$. $\mathrm{C}-$ $\mathrm{OH}$ 来自于水对石墨域边界处的氧化; $\mathrm{C}=\mathrm{O}$ 则主要来自 于反应物柠檬酸的残余基团. 此外, 由于表面含羟基, 通过氢键作用而吸附了大量水分子 $(532.1 \mathrm{eV})^{[26]}$.

氮、碳元素比 $(\mathrm{N} / \mathrm{C})$ 则随着柠檬酸和尿素质量比的 增大从 0.26 减小到 0.12 (表 1 ), 即橙色样品的氮含量高 于蓝色样品. 为了进一步分析 $\mathrm{N} 、 \mathrm{C}$ 元素的性质, 对 N1s 和 $\mathrm{C} 1 \mathrm{~s}$ 谱进行了卷积处理. 通过分峰拟合, 得到 N1s 精 细谱, 如图 $4 \mathrm{c}$ 所示. $398.8 \mathrm{eV}$ 处的峰来自碳氮杂环中 $\mathrm{sp}^{2}$ 杂化 $(\mathrm{C}=\mathrm{N}-\mathrm{C})$ 基团的 $\mathrm{N}^{[27]} ; 399.6 \mathrm{eV}$ 处的峰对应于 $\mathrm{sp}^{3}$ 杂化碳氮中的 $\mathrm{N}$, 即 $\mathrm{N}-(\mathrm{C})_{3}$ 基团中的桥连氮原子 ${ }^{[28]}$; $400.7 \mathrm{eV}$ 处的峰对应于氨基官能团 $\left(\mathrm{C}-\mathrm{NH}_{x}\right)$ 中的 $\mathrm{N}^{[29]}$. 三种颜色样品的 $\mathrm{N} 1 \mathrm{~s}$ 谱存在明显差别. 橙色样品在 $400.7 \mathrm{eV}$ 处的峰最弱, 表明样品含氨基最少, 这与红外 光谱结果相吻合. 蓝色样品在 $399.6 \mathrm{eV}$ 处的峰显著高于 橙色样品, 而在 $398.8 \mathrm{eV}$ 处的峰显著低于橙色样品, 这 表明蓝色样品形成了更多 $\mathrm{sp}^{3}$ 杂化的 $\mathrm{C}-\mathrm{N}$ 键, 而橙色样 品形成了更多 $\mathrm{sp}^{2}$ 杂化的 $\mathrm{C}-\mathrm{N}$ 键. 绿色样品的各特征峰 高度介于两者之间，说明其在结构上应该是属于橙、蓝 两种样品的过渡状态. 在 C1s 精细谱上也获得相应的结 果. 如图 $4 \mathrm{~b}$ 所示, $\mathrm{C} 1 \mathrm{~s}$ 谱也可以拟合出三个峰: 结合能 为 $284.6 \mathrm{eV}$ 处的峰归属于 $\mathrm{sp}^{2}$ 杂化 $(\mathrm{C}=\mathrm{C}-\mathrm{C})$ 中的碳 ${ }^{[30]}$, $286.8 \mathrm{eV}$ 处的峰对应于 $\mathrm{sp}^{3}$ 杂化 $(\mathrm{C}-\mathrm{N})$ 中的碳 ${ }^{[31]}, 288.6$ $\mathrm{eV}$ 处的峰来自于碳氮杂化环中 $\mathrm{sp}^{2}$ 杂化碳氮 $(\mathrm{C}=\mathrm{N}-\mathrm{C})$ 中的碳 ${ }^{[32]}$. 从 $\mathrm{C} 1 \mathrm{~s}$ 精细谱上来看, 三种样品中都含有一 定的石墨域; 在碳氮键方面, 橙色样品 $\mathrm{sp}^{2}$ 杂化的结构 多于蓝色样品, 而蓝色样品中 $\mathrm{sp}^{3}$ 杂化的结构多于橙色 样品. 绿色样品的结构特性介于两者之间.

综合 TEM、XRD、FTIR 和 XPS 的分析结果，对所 得不同颜色样品的微结构性质推测如下：所合成样品为 含石墨域(边界被氧化)的氮化碳聚合物，但各自具有一 定结构特点. 橙色样品尺寸小于 $10 \mathrm{~nm}$, 含大量 $\mathrm{sp}^{2}$ 杂化 的碳氮杂环(庚嗪环), 且残余氨基少, 说明其缩聚程度 较高, 应为典型氮化碳量子点. 蓝色样品的微观形貌是 由二维结构交错形成的三维网络, 除了含有 $\mathrm{sp}^{2}$ 杂化的 碳氮杂环外, 还形成了大量 $\mathrm{sp}^{3}$ 杂化的碳氮键, 其结构 更可能是碳氮杂环结构单元通过 $\mathrm{N}-(\mathrm{C})_{3}$ 基团中的 $\mathrm{N}$ 

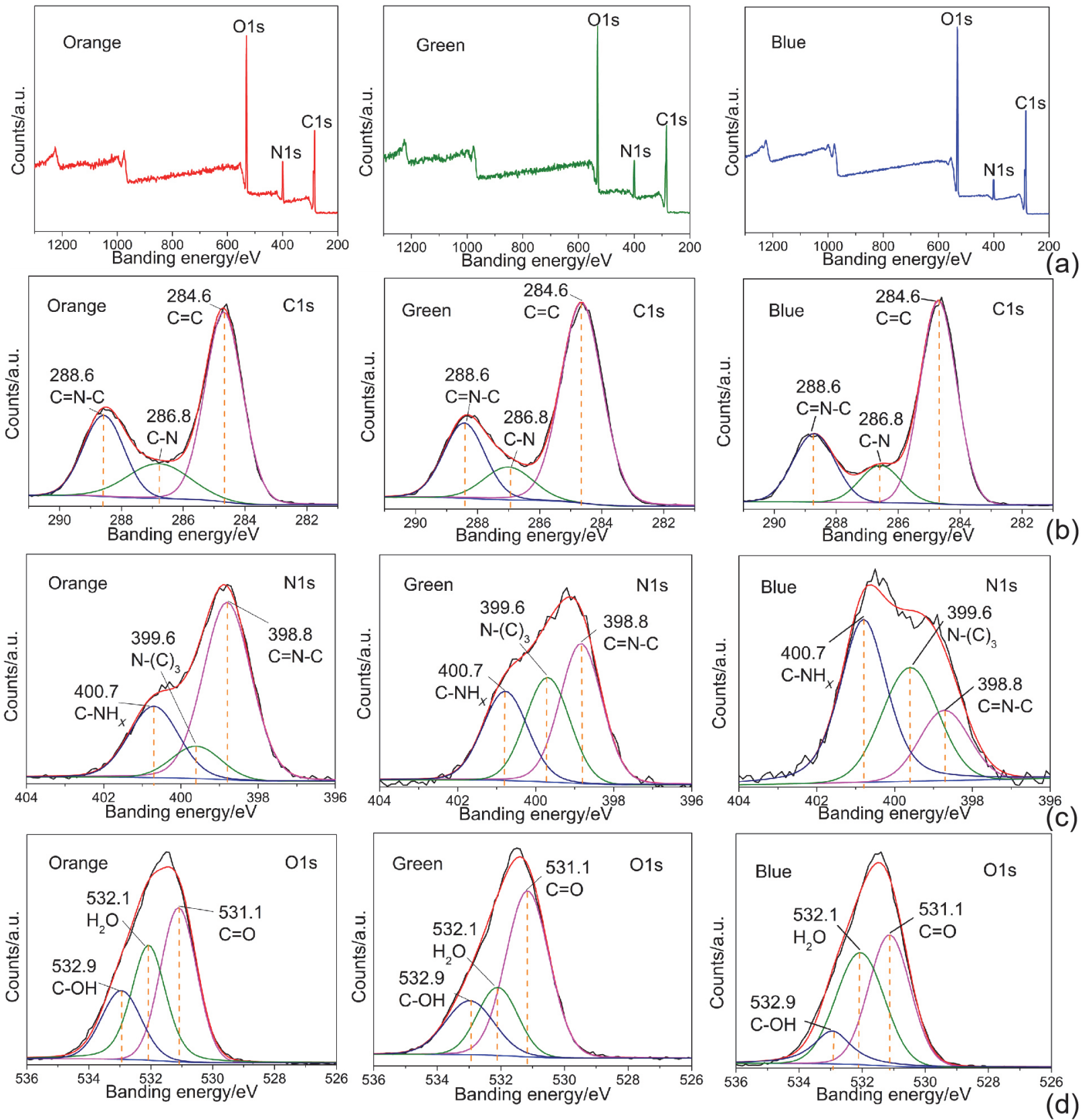

图 4 柠檬酸与尿素质量比分别为 $1: 10$ (橙色样品)、1:1(绿色样品)、1:0.5(蓝色样品)时所得产物的 XPS 图谱: (a) 总谱; (b) C1s 谱; (c) N1s 谱; (d) O1s 谱

Figure 4 XPS spectra of samples obtained when the mass ratios of citric acid to urea are $1: 10$ (orange sample), $1: 1$ (green sample), and $1: 0.5$ (blue sample): (a) survey spectra; (b) C1s; (c) N1s; (d) O1s

原子连接, 得到以三嗪环为基本结构单元的氮化碳. 绿 色样品则为介于橙色和蓝色样品之间的过渡态物质.

表 1 所合成不同颜色氮化碳的元素成分表

Table 1 Atomic percentage of $\mathrm{C}, \mathrm{N}$ and $\mathrm{O}$ of the sample

\begin{tabular}{|c|c|c|c|c|}
\hline & & Orange & Green & Blue \\
\hline \multirow{3}{*}{$\begin{array}{c}\text { Atomic ratio } \\
(\%)\end{array}$} & $\mathrm{C}$ & 54.18 & 55.97 & 57.35 \\
\hline & $\mathrm{N}$ & 13.87 & 12.22 & 7.11 \\
\hline & $\mathrm{O}$ & 30.36 & 29.34 & 32.7 \\
\hline \multicolumn{2}{|c|}{$\mathrm{N} / \mathrm{C}$} & 0.26 & 0.22 & 0.12 \\
\hline
\end{tabular}

\section{3 光电特性}

所合成不同颜色的氮化碳由于带隙大小的变化，而 具有显著可见光吸收, 这构成了光电转换的必要条件. 但材料被光激发后，能否获得有效的光生电子-空穴分 离, 则是光电转换的充分条件. 光致发射光谱可以从辐 射复合的角度，反映光激发产生的光生电子-空穴分离 情况. 为了探明样品被光激发后, 所产生的光生电子是 否与空穴复合, 进行了样品的苂光发射光谱(PL)测试. 结果发现, 三种颜色氮化碳的荧光发射都为弱信号(图 5a). 比较而言, 橙色样品的苂光发射信号最强, 而蓝色 

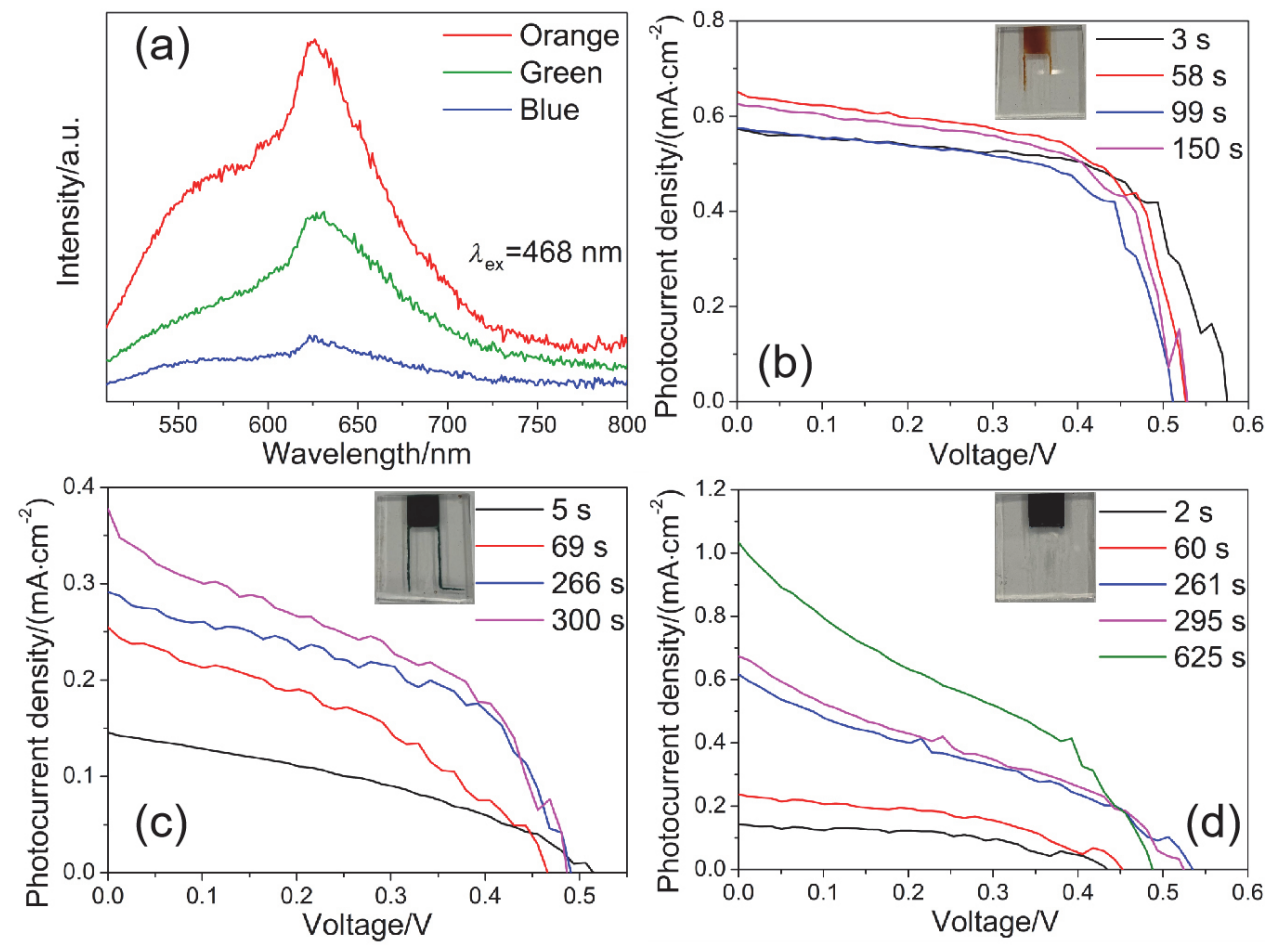

图 5 (a)不同颜色氮化碳的 PL 光谱(激发波长为 $468 \mathrm{~nm}$ ); (b)橙色氮化碳的 $J-V$ 曲线(插图为相应光电极); (c)绿色氮化碳的 $J-V$ 曲线(插图为相应光 电极); (c)蓝色氮化碳的 $J-V$ 曲线(插图为相应光电极)

Figure 5 (a) PL spectra of carbon nitrides with different color (excitation wavelength is $468 \mathrm{~nm}$ ); (b) $J$ - $V$ curve of the orange carbon nitride (the inset is corresponding photoelectrode); (c) $J$ - $V$ curve of the green carbon nitride (the inset is corresponding photoelectrode); (d) $J$ - $V$ curve of the blue carbon nitride (the inset is corresponding photoelectrode)

样品的最弱. 表明, 所合成的氮化碳材料均具备进行光 电转换的条件. 其中, 蓝色氮化碳因其光吸收最强(图 $1 b)$, 但荧光发射最弱, 而具有显著的光电转换优势.

采用 $\mathrm{TiO}_{2}$ 作为电子传输物质, 将所得氮化碳材料 涂覆在其表面, 制备成光电极(阳极); 载铂的导电玻璃 作为对电极(阴极); $\mathrm{LiI} / \mathrm{I}_{2}$ 溶于乙腈(含少量水)中作为电 解质, 组装成三明治结构的电池, 进行光电转换性能测 试. 在模拟 AM1.5 太阳光 $\left(100 \mathrm{~mW} \cdot \mathrm{cm}^{-2}\right)$ 的照射下, 扫 描了不同光照时间下电池的 $J-V$ 曲线. 测试结果表明, 橙色氮化碳具有典型光电转换的特征, 获得了 0.65 $\mathrm{mA} \cdot \mathrm{cm}^{-2}$ 的短路光电流密度 $\left(J_{\mathrm{sc}}\right), 530 \mathrm{mV}$ 的开路光电 压 $\left(V_{\mathrm{oc}}\right)$ 和 0.64 的填充因子 $(f f)$ (图 $5 \mathrm{~b}$ ). 绿色氮化碳的最佳 光电转换性能指标为: $J_{\mathrm{sc}}=0.36 \mathrm{~mA} \cdot \mathrm{cm}^{-2}, V_{\mathrm{oc}}=490 \mathrm{mV}$, $f f=0.41$, 表现出最差的光电转换性能(图 $5 \mathrm{c}$ ). 蓝色氮化 碳获得了最大 $1.03 \mathrm{~mA} \cdot \mathrm{cm}^{-2}$ 的 $J_{\mathrm{sc}}, V_{\mathrm{oc}}$ 为 $500 \mathrm{mV}, \mathrm{ff}$ 却最 低, 只有 0.33(图 5d). 值得注意的是, 蓝色氮化碳的短 路光电流随着光照时间的延长, 出现大幅增加; 而橙色 氮化碳却相对稳定. 表明两者的电极反应特性存在较大 差别. 为了进一步探明电极反应情况, 将所组装的电池 进行了电化学性能测试.

\section{4 光电化学特性}

将不同颜色氮化碳组装的电池以两电极模式, 分别 测试了光照和暗态条件下的循环伏安特性 $(\mathrm{CV})$ 和恒电
流充放电 $(\mathrm{GCD})$ 性能. 在 $0 \sim 1 \mathrm{~V}$ 电压范围内进行循环伏 安扫描发现, 在光照条件下, 橙色氮化碳电池获得的是 太阳能电池典型的电流电压特性, 其 $\mathrm{CV}$ 曲线上没有出 现任何氧化、还原电流峰(图 6a). 绿色氮化碳电池则在 $660 \mathrm{mV}$ 处出现氧化电流峰, 在 $495 \mathrm{mV}$ 处出现还原电流 峰(图 6b). 蓝色氮化碳电池在 $695 \mathrm{mV}$ 和 $500 \mathrm{mV}$ 处的这 一对氧化还原电流峰更加显著(图 6c). 绿色和蓝色氮化 碳表现出赝电容特性. 电池采用的电解质为 $\mathrm{I}_{2}$ 和 $\mathrm{LiI}$ 的 乙腈溶液(含少量水), 因此, $695 \mathrm{mV}$ 处的氧化电流峰应 该来自于 $\mathrm{I}^{-}+\mathrm{h}^{+} \rightarrow \mathrm{I}_{3}^{-}, 500 \mathrm{mV}$ 处的还原电流峰来自于 $\mathrm{I}_{3}^{-}+\mathrm{e}^{-} \rightarrow \mathrm{I}^{-}$. 值得注意的是, 在暗态, 这一对氧化还原 电流峰并未出现. 这说明, 绿色和蓝色氮化碳表现出的 赝电容行为确实是由光照引起的.

在 $0.4 \mathrm{~mA} \cdot \mathrm{cm}^{-2}$ 的电流密度下, 测试了电池在光照 和暗态下的 GCD 性能. 表现为光伏特性的橙色氮化碳 电池几乎没有充放电性能(图 6d). 具有诱导噟电容特性 的绿色和蓝色氮化碳电池产生了有效的充放电, 在 100 $\mathrm{mW} \cdot \mathrm{cm}^{-2}$ 光照下, 分别获得了 1.9 和 $4.9 \mathrm{mF} \cdot \mathrm{cm}^{-2}$ 的面 积比电容.

蓝色氮化碳具有显著的光诱导噟电容特性. 增大入 射光功率, 测试其在不同辐照度下的充放电性能(图 7a). 结果发现, 其面积比电容与入射光辐照度之间呈显著的 线性关系(图 7b), 随着入射光辐照度由 100 增大到 174 $\mathrm{mW} \cdot \mathrm{cm}^{-2}$, 其面积比电容由 4.9 增加到 $12 \mathrm{mF} \cdot \mathrm{cm}^{-2}$. 

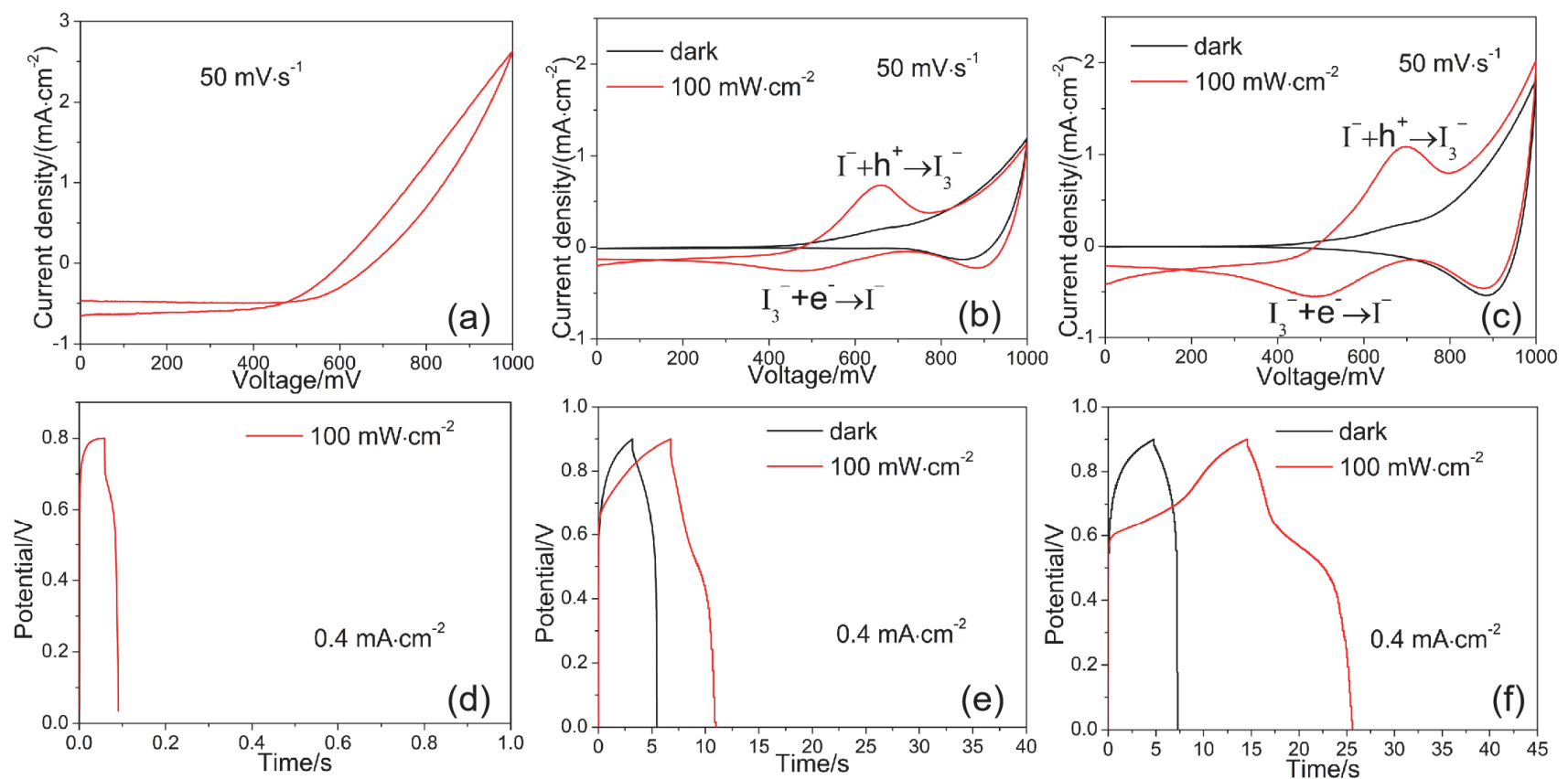

图 6 不同颜色氮化碳所组装的电池在光照 $\left(100 \mathrm{~mW} \cdot \mathrm{cm}^{-2}\right)$ 和暗态下进行电化学特性测试(固定电压扫描速度为 $50 \mathrm{mV} \cdot \mathrm{s}^{-1}$, 恒电流密度为 0.4 $\mathrm{mA} \cdot \mathrm{cm}^{-2}$ ): (a)橙色氮化碳电池在光照下的 $\mathrm{CV}$ 曲线; (b)绿色氮化碳电池在光照和暗态下的 CV 曲线; (c)蓝色氮化碳电池在光照和暗态下的 CV 曲 线; (d)橙色氮化碳电池在光照下的 GCD 曲线; (e)绿色氮化碳电池在光照和暗态下的 GCD 曲线; (f)蓝色氮化碳电池在光照和暗态下的 GCD 曲线

Figure 6 Electrochemical properties of the cells assembled with the colorful carbon nitrides are tested under light $\left(100 \mathrm{~mW} \cdot \mathrm{cm}^{-2}\right)$ and dark $($ voltage scanning speed is $50 \mathrm{mV} \cdot \mathrm{s}^{-1}$, constant current density is $0.4 \mathrm{~mA} \cdot \mathrm{cm}^{-2}$ ): (a) CV curve of the cell assemble with the orange carbon nitride under light; (b) $\mathrm{CV}$ curve of the cell assemble with the green carbon nitride under light and dark; (c) CV curve of the cell assemble with the blue carbon nitride under light and dark; (d) GCD curve of the cell assemble with the orange carbon nitride under light; (e) GCD curve of the cell assemble with the green carbon nitride under light and dark; (f) GCD curve of the cell assemble with the blue carbon nitride under light and dark
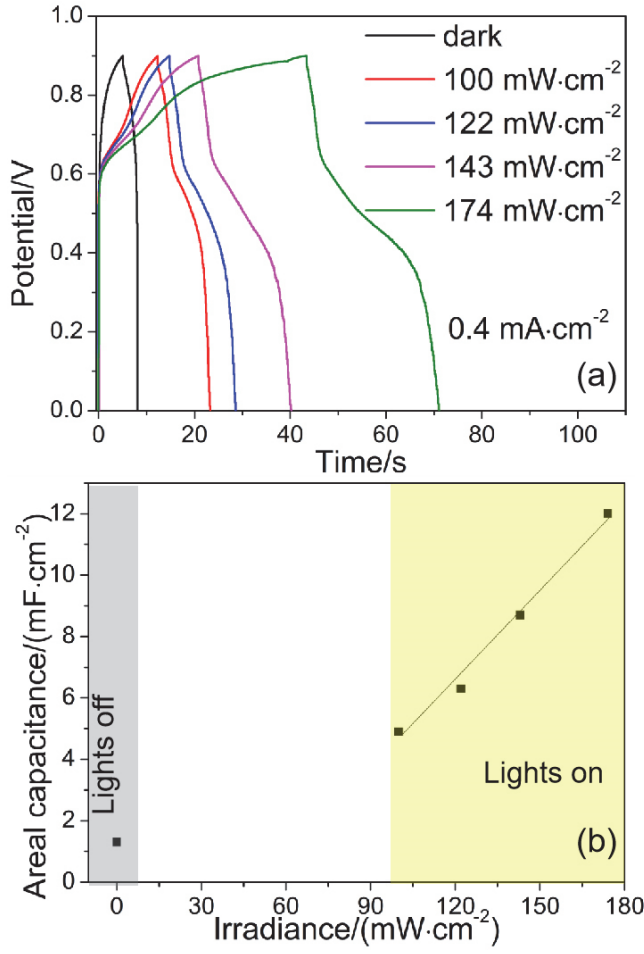

图 7 (a)蓝色氮化碳电池在不同太阳光辐照度下的恒电流充放电曲 线; (b)相应面积比电容与辐照度的关系

Figure 7 (a) GCD of the cells assemble with the blue carbon nitride tested under illumination with different irradiance; (b) relationship between the corresponding area specific capacitance and irradiance

\section{3 结论}

调控反应物中氮源(尿素)和碳源(柠檬酸)的比例, 是在氮化碳中引入石墨域的有效方法; 采用室温熟化工 艺, 可以使氮化碳形成三嗪环为结构单元的微结构, 并 可获得有序二维纳米网络的微观形态. 由于微结构的调 控，使氮化碳的带隙值从 $2.26 \mathrm{eV}$ 降低为 $1.74 \mathrm{eV}$, 表现 出对 550 700 nm 波段可见光的强吸收. 具有不同带隙 值和微结构性质的氮化碳，表现出不同的光电化学特 性. 橙色氮化碳 $\left(E_{\mathrm{g}}=2.26 \mathrm{eV}\right)$ 具有典型光伏特征, 由于 光吸收较弱, 只获得了 $0.65 \mathrm{~mA} \cdot \mathrm{cm}^{-2}$ 的短路光电流密 度 $\left(J_{\mathrm{sc}}\right), 530 \mathrm{mV}$ 的开路光电压 $\left(V_{\mathrm{oc}}\right)$ 和 0.64 的填充因子 $(f f)$. 蓝色氮化碳 $\left(E_{\mathrm{g}}=1.74 \mathrm{eV}\right)$ 则表现出少见的光诱导赝 电容特性，且其面积比电容与入射光辐照度之间呈显著 的线性关系，随着入射光辐照度由 100 增大到 174 $\mathrm{mW} \cdot \mathrm{cm}^{-2}$, 面积比电容由 4.9 增加到 $12 \mathrm{mF} \cdot \mathrm{cm}^{-2}$.

\section{4 实验部分}

\section{1 样品制备}

采用柠檬酸和尿素为反应物制备氮化碳. 分别称取 柠檬酸 $0.05 \mathrm{~g}$ 、尿素 $0.5 \mathrm{~g}$ 溶解于 $60 \mathrm{~mL}$ 水中, 将混合溶 液倒入 $100 \mathrm{~mL}$ 反应釜中，在 $200{ }^{\circ} \mathrm{C}$ 下水热反应 $3 \mathrm{~h}$ ，得 到前驱体溶液. 再分别称取柠檬酸 $0.5 \mathrm{~g}$ 、尿素 $0.5 \mathrm{~g}$ 和 柠檬酸 $1.17 \mathrm{~g}$ 、尿素 $0.6 \mathrm{~g}$, 重复上述实验步骤. 将得到 
的前驱体溶液置于黑暗环境中, 室温熟化 $30 \mathrm{~d}$, 分别得 到橙色、绿色、蓝色透明溶液. 将透明溶液在 $-80{ }^{\circ} \mathrm{C}$ 下 冷冻干燥处理, 得到橙色、绿色、蓝色固体样品.

\section{2 微结构表征}

紫外-可见吸收光谱和透射光谱采用紫外可见分光 光度计(Cary5000)测试. 将橙、绿、蓝三种颜色样品稀 释, 滴在碳膜上, 进行样品的 TEM 测试(JEM-2100F), 观察样品的微观形态. 采用冷冻干燥的固体样品进行 XRD、FTIR、XPS 测试. XRD 分析样品的晶体结构 (XD-2), 靶材为 $\mathrm{Cu}$ 靶, 工作电压为 $36 \mathrm{kV}$, 工作电流为 $20 \mathrm{~mA}$. FTIR (Cary630)分析样品表面官能团. XPS (ESCALAB250Xi) 分析样品表面元素组成及成键性质.

\section{3 电极制备及电池组装}

将 $\mathrm{TiO}_{2}$ 烧结在 $\mathrm{FTO}$ 导电玻璃上, 作为电子传输层; 再将干燥氮化碳样品加少量水, 调制成浓稠浆料, 直接 涂覆在 $\mathrm{TiO}_{2}$ 上, 室温下晾干制备成光电极(阳极). 载铂 的 FTO 导电玻璃作为对电极 (阴极). 将光电极和铂电极 相对夹紧, 在其间填充电解质溶液 $\left(0.07 \mathrm{~g} \mathrm{LiI}\right.$ 和 $0.7 \mathrm{~g} \mathrm{I}_{2}$ 溶于 $4.5 \mathrm{~mL}$ 乙腈和 $0.5 \mathrm{~mL}$ 水的混合溶剂), 组装成三明 治结构的电池.

\section{4 光电化学性能测试}

在模拟 AM 1.5 太阳光 $\left(100 \mathrm{~mW} \cdot \mathrm{cm}^{-2}\right)$ 的照射下，测 试电池的 $J-V$ 曲线(CEL-IV), 分析电池的光电转换性能. 采用两电极模式测试循环伏安特性曲线 $(\mathrm{CV})$ 和恒电流 充放电曲线(GCD) (CHI600C).

\section{References}

[1] Ma, C.; Wu, J.; Zhu, L.; Han, X.; Ruan, W.; Song, W.; Wang, X.; Zhao, B. Acta Chim. Sinica 2019, 77, 1024 (in Chinese). (马超, 武 佳炜, 朱琳, 韩晓霞, 阮伟东, 宋薇, 王旭, 赵冰, 化学学报, 2019, 77, 1024.)

[2] Su, S.-J.; Lai, Q.-X.; Liang, Y.-Y. Acta Chim. Sinica 2015, 73, 735 (in Chinese). (苏善金, 来庆学, 梁彦瑜, 化学学报, 2015, 73, 735.)

[3] Yang, H.; Wang, Z.; Liu, S.-Q.; Shen, Y.-F.; Zhang, Y.-J. Chin. Chem. Lett. 2020, 31, 3047.

[4] Hou,Y.; Wen, Z.; Cui, S.; Guo, X.; Chen, J. Adv. Mater. 2013, 25, 6291.

[5] Wang, X.; Maeda, K.; Thomas, A.; Takanabe, K.; Xin, G.; Carlsson, J. M.; Domen, K.; Antonietti, M. Nat. Mater. 2009, 8, 76.

[6] Yang, X.-H.; Wang, H.-J.; Lu, X.-F.; Cui, D.-L.; Zhang, S.-Y. Acta Chim. Sinica 2009, 67, 1166 (in Chinese). (杨晓轫, 王红军, 陆希 峰，崔得良，张树永，化学学报, 2009, 67, 1166.)
[7] Li, F.; Tang, M.; Li, T.; Zhang, L.; Hu, C. Appl. Catal., B: Environ. 2020, 268, 118397

[8] Hao, X.-Q.; Yang, H.; Jin, Z.-L.; Xu, J.; Min, S.-X.; Lü, G.-X. Acta Phys.-Chim. Sin. 2016, 32, 2581 (in Chinese). (郝旭强, 杨浩, 靳治 良, 续京, 敏世雄, 吕功煊, 物理化学学报, 2016, 32, 2581.)

[9] Su, P.; Guo, H.-L.; Peng, S.; Ning, S.-K. Acta Phys.-Chim. Sin. 2012, 28, 2745 (in Chinese). (苏鹏，郭慧林，彭三，宁生科，物理 化学学报, 2012, 28, 2745.)

[10] Safaei, J.; Mohamed, N. A.; Noh, M. F. M.; Soh, M. F.; Ludin, N. A.; Ibrahim, M. A.; Roslam, W. N.; Isahakb, W.; Teridi, M. A. M. J. Mater. Chem. A 2018, 6, 22346.

[11] Li, Z.; Wu, S.; Zhang, J.; Yuan, Y.; Wang, Z.; Zhu, Z. Solar RRL 2019, 4, 1900413.

[12] Liu, J.; Zhang, Y.; Zhang, L.; Xie, F.; Vasileff, A.; Qiao, S. Adv. Mater. 2019, 31, 1901261

[13] Kong, D.; Gao, Y.; Xiao, Z.; Xu, X.; Li, X.; Zhi, L. Adv. Mater. 2018, 31, 1804973.

[14] Inagaki, M.; Tsumura, T.; Kinumoto, T.; Toyoda, M. Carbon 2019, 141,580 .

[15] Zhao, T.-T.; Zhou, Q.; Lv, Y.-Q.; Han, D.; Wu, K.-Q.; Zhao, L.-F.; Shen, Y.-F.; Liu, S.-Q.; Zhang, Y.-J. Angew. Chem. Int. Ed. 2019, 59, 1139 .

[16] Qi, S.; Ma, X.; Yang, B.; Sun, L.; Li, W.; Zhao, M. Carbon 2019 , $149,234$.

[17] Algara-Siller, G.; Severin, N.; Chong, S. Y. Angew. Chem. Int. Ed. 2014, 53, 7450

[18] Kumar, P.; Vahidzadeh, E.; Thakur, U. K.; Kar, P.; Alam, K. M.; Goswami, A.; Mahdi, N.; Cui, K.; Bernard, G. M.; Michaelis, V. K.; Shankar, K. J. Am. Chem. Soc. 2019, 141, 5415.

[19] Lin, L.; Yu, Z.; Wang, X. Angew. Chem. Int. Ed. 2019, 58, 6164.

[20] Yang, Q.; Yu, S.; Fu, P.; Yu, W.; Liu, Y.; Liu, X.; Feng, Z.; Guo, X.; Li, C. Adv. Funct. Mater. 2020, 30, 1910205.

[21] Mo, Z.; Xu, H.; Chen, Z.; She, X.; Song, Y.; Lian, J.; Zhu, X.; Yan, P.; Lei, Y.; Yuan, S.; Li, H. Appl. Catal., B 2019, 241, 452.

[22] Zheng, F.; Yang, Y.; Chen, Q. Nature Commun. 2014, 5, 1.

[23] Si, Y.; Samulski, E. T. Nano Lett. 2008, 8, 1679.

[24] Podjaski, F.; Kröger, J.; Lotsch, B. V. Adv. Mater. 2018, 30, 1705477.

[25] Geng, D.; Yang, S.; Zhang, Y.; Yang, J.; Liu, J.; Li, R.; Sham, T.; Sun, X.; Ye, S.; Knights, S. Appl. Surf. Sci. 2011, 257, 9193.

[26] Hu, C.; Liu, Y.; Yang, Y.; Cui, J.; Huang, Z.; Wang, Y.; Yang, L.; Wang, H.; Xiao, Y.; Rong, J. J. Mater. Chem. B 2013, 1, 39.

[27] Usachov, D.; Vilkov, O.; Grüneis, A.; Haberer, D.; Fedorov, A.; Adamchuk, V. K.; Preobrajenski, A. B.; Dudin, P.; Barinov, A.; Oehzelt, M.; Laubschat, C.; Vyalikh, D. V. Nano Lett. 2011, 11, 5401.

[28] Xu, J.; Xu, F.; Qian, M.; Xu, F.; Hong, Z.; Huang, F. Adv. Mater. 2017, 29, 1701674

[29] Hou, S.; Cai, X.; Wu, H.; Yu, X.; Peng, M.; Yan, K.; Zou, D. Energy Environ. Sci. 2013, 6, 3356.

[30] Papailias, I.; Todorova, N.; Giannakopoulou, T.; Ioannidisa, N.; Dallasa, P.; Dimotikalib, D.; Trapalis, C. Appl. Catal. B: Environ. 2020, 268, 118733 .

[31] Hu, X.; Zeng, X.; Liu, Y.; Lu, J.; Yuan, S.; Yin, Y.; Hu, J.; McCarthy, D. T.; Zhang, X. Appl. Catal. B: Environ. 2020, $268,118466$.

[32] Ong, W.-J.; Tan, L.-L.; Chai, S.-P. Nano Energy 2015, 13, 757.

(Cheng, B.) 